\title{
Comparison between bubbling and turbulent regime for the simulation of batch pharmaceutical powders fluidized bed drying
}

\author{
Zammouri, A. ${ }^{\text {a*}}$; Boudhrioua Mihoubi, N. ${ }^{\text {b }}$ Kechaou, N.c \\ ${ }^{\text {a }}$ Laboratoire de Biotechnologie et Valorisation des Bio-Géo Ressources, LR11ES31. Institut Supérieur \\ de Biotechnologie de Sidi Thabet, Univ. Manouba, BP-66, 2020 Ariana-Tunis, Tunisie,. \\ b Laboratoire de Physiopathologies, Alimentation et Biomolécules, LR17ES03. Institut \\ Supérieur de Biotechnologie de Sidi Thabet, Univ. Manouba, BP-66, 2020 Ariana-Tunis, \\ Tunisie, \\ c Groupe de Recherche en Génie des Procédés Agroalimentaires, Ecole Nationale \\ d’Ingénieurs de Sfax, Université de Sfax, BP 1173 3038, Sfax, Tunisie. \\ * E-mail of the corresponding author : amel.zammouri@gmail.com
}

\begin{abstract}
The two-phase theory has been frequently used to model fluidised bed drying. At high air velocities, a transition from the bubbling regime to the turbulent regime may occur. In this work, we compare a bubbling model and a turbulent model for the simulation of a two pharmaceutical powders drying in a pilot plant and an industrial plant fluidised bed. The bubbling model was based on a discrete variable bubble size. Heat and mass transfer coefficients were based on the Kunii and Levenspiel correlation [1]. Flow regime was supposed to be completely mixed for the emulsion phase. For the turbulent model, the bubble size is not anymore discrete but continuous and bubble phase is less distinguishable than in the bubbling regime. Heat and mass transfer were those proposed by Foka[2]. In addition, the freeboard section was considered since high entrainment is specific of this regime. Gas backmixing was taken into account by considering a plug flow with axial dispersion for the interstitial gas flow. The bubble phase being dilute, was modeled by a plug flow. A plug flow was also considered for the freeboard gas. The solid phase was supposed to be completely mixed. The bubbling regime simulation gave good agreement with experiment in the case of the pilot plant experiment, while the turbulent model better simulated the industrial scale experiment.
\end{abstract}

Key words: batch fluidized bed, pharmaceutical powder, drying, modeling, bubbling, turbulent 


\section{Introduction}

Drying of pharmaceutical products is frequently carried in batch fluidized bed dryers. Fluidisation offers the advantage of high heat and mass transfer rates due to the elevated specific surface area created. Generally, the drying end is determined by analyzing the moisture content at different times. Several works [3-4] proved that more rigorous control could be obtained by mathematical modeling. Models proposed considered either bubbling regime or turbulent regime fluidisation. The transition between these two regimes, at high air velocities, should be better experimentally determined. Correlations proposed to determine the transition velocity depend generally on experimental system used. In this work, a bubbling regime model based on the two phase theory is compared to a turbulent regime model for the simulation of the drying kinetics of an A type particles and a B type particles pharmaceutical powders. Sorption isotherms determined experimentally were used to describe the falling drying rate period.

\section{Experimental study}

\subsection{Material properties}

The drying experiments were carried with two pharmaceutical products supplied by Pharmaghreb industry (Tunisia), an A type particles (Hypril) and a B type particles (Azix).

\subsection{Equilibrium sorption study}

Sorption isotherms of the two products were determined by contacting the solid samples with air at a variety of relative humidity at a fixed temperature. Equilibrium water sorption was measured, at different temperatures, by static gravimetric method with sulfuric acid solutions at different concentrations.

\subsection{Drying kinetic study}

Fluidized bed-drying experiments for group A type particles were carried in a Diosna MinilabXP (Germany). conical laboratory scale bed. Drying kinetics for group B type particles were obtained from a Glatt WSD-CD-30(USA) conical industrial scale fluidized bed . Experimental conditions are listed in table 1. Air heated at the desired temperature was supplied at the bottom of the conical chamber. The bed temperature was on line measured. The solid moisture content was determined by a moisture analyser (Mettler Toledo, Switzerland).

At the beginning of the fluidized bed experiments, the A type powder was initially very cohesive showing a Geldart $C$ powder characteristics. The entire bed mass rose as plug when hot air was blown into the bed. After a short time of drying, the moisture content decreased, the Geldart C type cohesive powder shifts to a Geldart A powder. The plug was broken manually and a fluidization state was attained. The same trend was obtained for B type particles. 
Table 1. Experimental conditions and physical materiel properties

\begin{tabular}{lll}
\hline Geldart group & A & B \\
\hline Mean diameter $(\mu \mathrm{m})$ & 48.8 & 384.72 \\
Density $\left(\mathrm{kg} / \mathrm{m}^{3}\right)$ & 649.35 & 702 \\
Superficial air velocity $(\mathrm{m} / \mathrm{s})$ & 0.97 & 2.26 \\
Inlet air temperature $\left({ }^{\circ} \mathrm{C}\right)$ & 47 & 50 \\
Initial air temperature $\left({ }^{\circ} \mathrm{C}\right)$ & 24 & 18.4 \\
Relative humidity $(\%)$ & 60 & 60 \\
Initial solid moisture $($ dry basis,\% $)$ & 29.55 & 19.74 \\
Critical moisture (dry basis, $\%)$ & 13,00 & 4.00 \\
Solid mass (wet basis, kg) & 1 & 36.9 \\
Column diameter(m) & 0.16 & 0.5 \\
Column height $(\mathrm{m})$ & 0.5 & 2.0 \\
\hline
\end{tabular}

\section{Mathematical modeling}

\subsection{Bubbling regime model}

The behaviour of the fluidized bed dryer is based on the two-phase theory: a bubble phase and an emulsion phase [1, 3]. The emulsion phase is at minimum fluidisation conditions and consists of interstitial gas and solid phase. Due to the buoyancy force, all the gas in excess of minimum fluidisation by passes the particles and rises through the bed as bubbles containing very small amount of solids. The governing equations are the equations of mass and heat conservation for bubble phase, interstitial gas and solid emulsion phase. These equations are detailed in $[3,4]$. The bubble diameter is a key parameter in the modeling of a bubbling fluidised bed and have a great importance on its performance. Several correlations were proposed to calculate the bubble diameter. For B type particles, the Darton's [5] correlation is largely used, it takes account of bubbles coalescing as they rise in the bed.

For A type particles, the correlation proposed by Horio and Nonaka [6] is selected. The authors proved that, for fine particles, a stable equilibrium bubble size could be obtained due to their successive coalescence and splitting. 


\subsection{Turbulent regime model}

The turbulent regime is characterised by a breakup of coalesced bubbles to smaller ones. The large bubble renewal frequency caused by coalescing and splitting leads to a better interchange between bubbles and interstitial gas. The bubble size decrease reduces the short cut leading so to less gas back mixing and an increase in the gas solid contact. At the same time, the solids back mixing is also violent in turbulent fluidization. Experimental evidence [7] proved that gas flow is intermediate between an ideal plug flow and ideal agitated flow. As the bubbles erupt at the bed surface, they burst and particles splash into freeboard above the bed. At high velocities, high entrainment is produced. The particles are carried over in the freeboard. Two regions coexist in the bed:

- A bottom dense bed region with a high solid concentration and overall voidage $\varepsilon$

- An upper dilute freeboard region with an axial variable voidage $\varepsilon_{z}$

\subsubsection{Dense bed balance equations}

The equations for the bubbling regime can be extended to the turbulent fluidization with no distinct bubble phase, but rather low and high-density phases with a different bubble phase voidage.

Dense phase interstitial gas mass balance

The dense phase is no longer at the minimum fluidisation conditions and voidage $\varepsilon_{\mathrm{d}}$ is greater than $\varepsilon_{\mathrm{mf}}$ because of solid entrainment. Axial dispersion is considered and mass and heat transfer coefficients between the low and high density phases are different than those used for discrete bubbles.

$$
\begin{aligned}
\rho_{G} u_{d} \frac{\partial x_{e}}{\partial z}+D_{a x} \rho_{G} \varepsilon_{d}\left(1-\delta_{b}\right) \frac{\partial^{2} x_{e}}{\partial z^{2}}-K_{b e} \rho_{G} \delta_{b}\left(x_{e}-x_{b}\right) \\
+\left(1-\varepsilon_{d}\right)\left(1-\delta_{b}\right) \frac{6}{d_{p}} \sigma\left(x_{p}^{*}-x_{e}\right)=\varepsilon_{d}\left(1-\delta_{b}\right) \rho_{G} \frac{\partial x_{e}}{\partial t}
\end{aligned}
$$

Where $x_{e}$ is the moisture content of the dense phase interstitial gas on dry basis $(\mathrm{kg} / \mathrm{kg})$ and $\mathrm{x}_{\mathrm{p}}{ }_{\mathrm{p}}$ is the moisture content of drying gas on particle surface. $\sigma$ is evaporation coefficient $\left(\mathrm{kg} \mathrm{m}^{-2} \mathrm{~s}^{-1}\right) . \varepsilon_{\mathrm{d}}$ is the dense phase voidage and $\delta_{\mathrm{b}}$ is the lean phase voidage. $\mathrm{D}_{\mathrm{ax}}$ is the axial dispersion coefficient $\left(\mathrm{m}^{2} / \mathrm{s}\right)$.

At the bed entrance and exit the Danckwerts Boundary conditions were used for the axial dispersed low. 
Dense phase interstitial gas energy balance

$$
\begin{aligned}
-\rho_{G} u_{d}\left(c_{G}+x_{o} c_{v}\right) & \frac{\partial T_{e}}{\partial z}+k_{g} \varepsilon_{d}\left(1-\delta_{b}\right) \frac{\partial^{2} T_{e}}{\partial z^{2}}-H_{b e} \rho_{G} \delta_{b}\left(T_{e}-T_{b}\right) \\
- & \left(1-\varepsilon_{d}\right)\left(1-\delta_{b}\right) \frac{6}{d_{p}}\left(T_{e}-T_{p}\right)\left[c_{v} \sigma\left(x_{p}^{*}-x_{e}\right)\right. \\
& \left.+h_{p}\right]-\frac{1}{A_{c} d z} h_{w} S_{w}\left(T_{e}-T_{w}\right)=\varepsilon_{d}\left(1-\delta_{b}\right) \rho_{G}\left(c_{G}+x_{e} c_{v}\right) \frac{\partial T_{e}}{\partial t}
\end{aligned}
$$

The interphase mass transfer coefficient $\left(\mathrm{s}^{-1}\right)$ is given by a correlation proposed by [2]

$$
K_{b e}=1.631 S_{c}^{0.37} u_{o}
$$

The heat transfer coefficient $\mathrm{H}_{\mathrm{be}}\left(\mathrm{w} / \mathrm{m}^{3} . \mathrm{K}\right)$ determined by the Chilton-Colburn analogy.

The dense bed voidage and Peclet number are correlated as proposed by [7]:

Dense phase solid mass balance

The axial dispersion in the turbulent regime increases largely with the gas velocity giving up an homogeneous solid phase in the bed. The following equations describe mass and heat transfer between solid and interstitial gas.

$$
\begin{gathered}
-\frac{\rho_{s}}{1+\frac{\rho_{s}}{\rho_{w}} x_{c}} \frac{\partial x_{p}}{\partial t}=\frac{6}{d_{p}} \sigma\left(x_{p}^{*}-x_{e}\right)+\frac{\rho_{s}}{1+\frac{\rho_{s}}{\rho_{w}} x_{c}} D_{s} \frac{\partial^{2} x_{p}}{\partial z^{2}} \\
\frac{6}{d_{p}} h_{p}\left(T_{e}-T_{p}\right)-\frac{6}{d_{p}} \sigma\left(x_{p}^{*}-x_{e}\right)\left[\gamma_{o}+c_{v}\left(T_{e}-T_{r e f}\right)-c_{w}\left(T_{e}-T_{r e f}\right)\right]+k_{s} \frac{\partial^{2} T_{p}}{\partial z^{2}} \\
=\frac{\rho_{s}}{1+\frac{\rho_{s}}{\rho_{w}} x_{c}}\left(c_{p}+x_{p} c_{w}\right) \frac{\partial T_{p}}{\partial t}
\end{gathered}
$$

\subsubsection{Freeboard balance equations}

The plug flow model is used to describe the drying upper dilute region or freeboard. The mass and heat balance for the gas phase are:

$$
\begin{gathered}
-\rho_{G} u_{o} \frac{\partial x_{f}}{\partial z}++\left(1-\varepsilon_{z}\right) \frac{6}{d_{p}} \sigma\left(x_{p}^{*}-x_{f}\right)=\varepsilon_{z} \rho_{G} \frac{\partial x_{f}}{\partial t} \\
-\rho_{G} u_{o}\left(c_{G}+x_{o} c_{v}\right)-\left(1-\varepsilon_{z}\right) \frac{6}{d_{p}}\left(T_{f}-T_{p}\right)\left[c_{v} \sigma\left(x_{p}^{*}-x_{f}\right)+h_{p}\right] \\
-\frac{1}{A_{c} d z} h_{w} S_{w}\left(T_{f}-T_{w}\right)=\varepsilon_{z} \rho_{G}\left(c_{G}+x_{e} c_{v}\right) \frac{\partial T_{f}}{\partial t}
\end{gathered}
$$

Several correlations were proposed to determine solid decay in the freeboard, but they give predictions that differs each from others. However, it is largely accepted that concentration in the freeboard decreases exponentially with height. 
Comparison between bubbling and turbulent regime for the simulation of batch pharmaceutical powders fluidized bed drying

$$
\frac{\varepsilon^{*}-\varepsilon_{z}}{\varepsilon^{*}-\varepsilon}=\exp \left(-a_{z} *\left(z-h_{i}\right)\right.
$$

$\varepsilon$ is the de dense bed voidage. $\varepsilon_{\mathrm{z}}$ is the freeboard voidage at z. $\varepsilon^{*}$ is the asymptotic voidage at $\mathrm{z} \rightarrow \infty$ in the dilute region.

$$
\varepsilon_{z}=\varepsilon^{*}-\left(\varepsilon^{*}-\varepsilon\right) \exp \left(-a_{z} *\left(z-h_{i}\right)\right.
$$

The position of the point of inflexion $h_{i}$ separating the dilute and dense bed regions can be calculated in a trial manner using the solids inventory in the dryer.

\section{Results and discussion}

The set of ordinary derivatives thus obtained was solved with Matlab solver(MALAB R2012b). For the group A type particles and B type particles, the moisture sorption isotherms obtained experimentally were fitted by the modified-Hendersen correlation:

$$
\begin{aligned}
R H_{A}=\frac{P_{v}}{P_{w}} & =1-\exp \left(-0.0298 *\left(T_{p}-90.94\right) X_{p}^{0.78}\right) \\
R H_{B} & =\frac{P_{v}}{P_{w}}=1-\exp \left(-465.2 *\left(T_{p}+231.8\right) X_{p}^{3.64}\right)
\end{aligned}
$$

$\mathrm{RH}$ is the relative humidity, $\mathrm{T}_{\mathrm{p}}$ is the particle temperature and $\mathrm{X}_{\mathrm{p}}$ is solid moisture content on dry basis $(\mathrm{kg} / \mathrm{kg})$.

The comparison between solid moisture content simulations as function of time for bubbling and turbulent regime models to experimental results is illustrated in Fig.1 and Fig.2. For A type particles, bubbling regime gives better fitting of experimental results than turbulent one. The latter regime overestimates the drying rate. The completely mixed flow is more realistic than the axially dispersed flow. For B type particles, the bubble diameter was calculated by Darton correlation. [1] suggested that a constant bubble diameter value of $0.05 \mathrm{~m}$ could be convenient for the simulations. [4] obtained good predictions with a constant bubble diameter of $0.06 \mathrm{~m}$ and an air superficial velocity of $2.4 \mathrm{~m} / \mathrm{s}$. The equivalent bubble diameter value obtained with (2) for A type particles was also $0.06 \mathrm{~m}$. A simulation with this diameter was so tried. It is noted that Darton correlation largely underestimated the drying rate. This is due to the growth of bubble size by coalescence as they rise in the bed which causes mass and heat transfer decrease. At high superficial velocities, splitting of bubbles occur and constant equivalent bubble diameter is more realistic. However the turbulent regime is more 
convenient for this powder and gives the better prediction of experimental data. This regime is characterised by considerable solid entrainment in the freeboard zone.

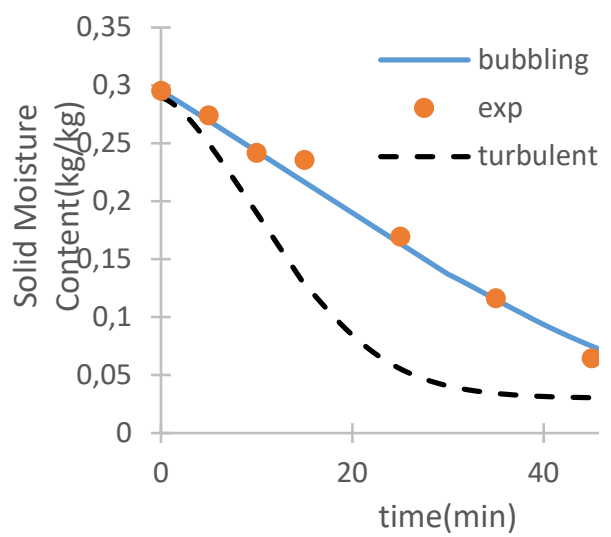

Fig.1 Simulated and experimental solid moisture as function of time (A type particles)

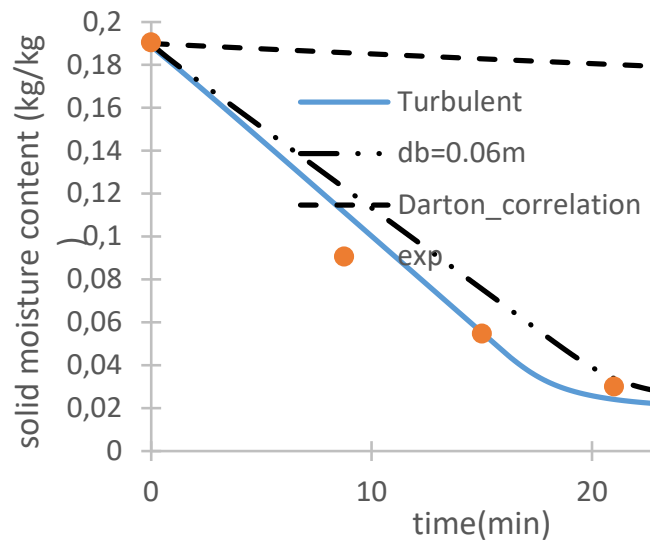

Fig.2 Simulated and experimental solid moisture content as function of time(B type particles)

While the solid concentration in this section is very dilute relatively to the dense region (Fig. 3), drying continues in the freeboard region. From Fig.4, it can be noted that air moisture content in the dense bed is higher than that in the freeboard zone. Moisture is driven more efficiently to air in the dense bed but freeboard contributes also to performing drying kinetics. Freeboard contribution becomes more important as the product is dried in the falling rate period where there is no more surface water. The same trend was found by [8].

To ensure homogenous solid moisture content in the bed, axial dispersion was added to solid mass and heat balances. To test the influence of axial solid dispersion coefficient, four values were assigned to Ds: 10, $1,0.1$ and $0.01 \mathrm{~m}^{2} / \mathrm{s}$. The simulations results of solid moisture content variation with time and with axial coordinates are presented in Fig.5 and Fig.6. Closer inspection of these figures shows that for Ds values, $0.1,1$ and $10 \mathrm{~m}^{2} / \mathrm{s}$ solid particles are perfectly mixed and there is no influence of Ds value on solid moisture content as function of time. This is in well agreement with the results of [9] where Ds values were stated to be in the range $0.5-10 \mathrm{~m}^{2} / \mathrm{s}$. In this work a Ds value of $1 \mathrm{~m}^{2} / \mathrm{s}$ was used for all simulation as suggested by [2]. For the lowest Ds value $0.01 \mathrm{~m}^{2} / \mathrm{s}$, an axial solid moisture content dispersion appears and a little deviation from experimental data is obtained.

\section{Conclusions}

A comparison between bubbling regime and turbulent regime batch-fluidized bed drying of an A and a B pharmaceutical powders has been made. Simulation results show that the experimental drying kinetic is better predicted by the bubbling regime in the case of the $\mathrm{A}$ type particles while for the B type particles turbulent regime model is more convenient 
Comparison between bubbling and turbulent regime for the simulation of batch pharmaceutical powders fluidized bed drying

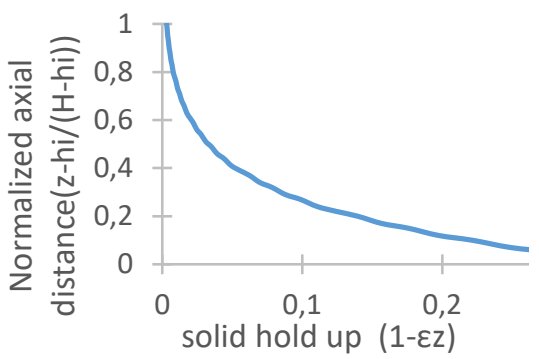

Fig.3 Solid hold up profile in the freeboard for B type particles

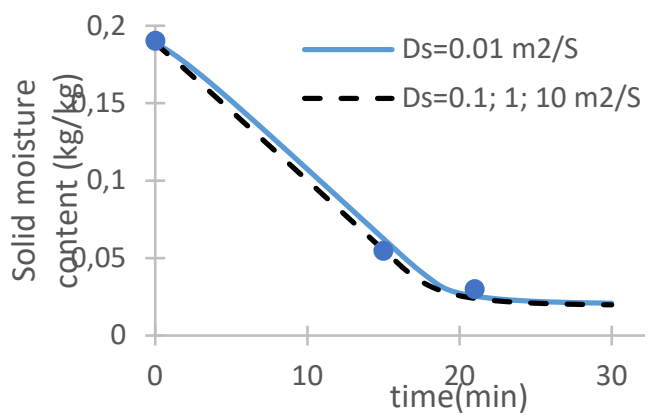

Fig.5: Simulated solid moisture content function of time at different $D s$

as

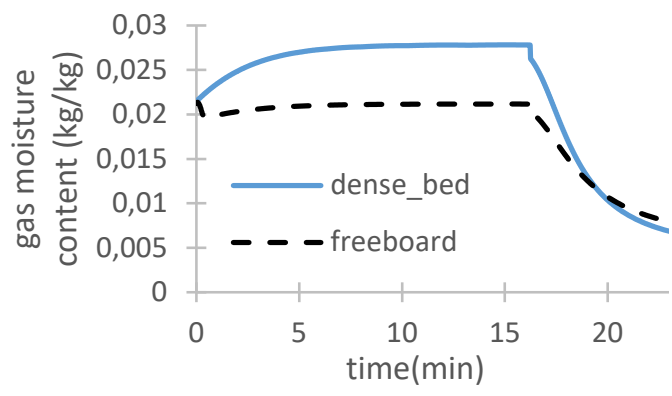

Fig.4 Simulated gas moisture content in dense phase and freeboard as function of time (B particle)

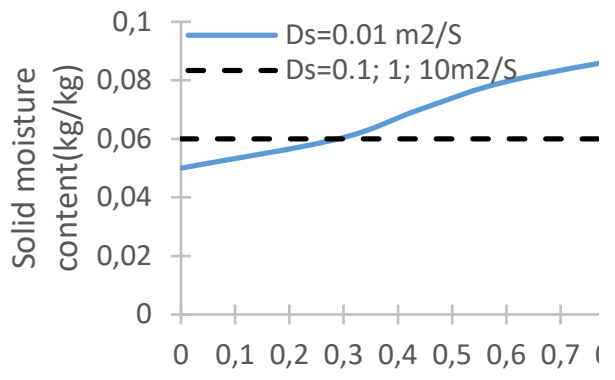

normalized axial distance z-hi/(H-hi)

Fig.6: Simulated solid moisture content as function of axial distance at different $D s$

\section{References}

[1] Kunii, D.; Levenspiel, O. Fluidization Engineering. Wiely: New York, 1969

[2] Foka, M.; Chaouki, J., Guy C., Klvana, D. Gas phase hydrodynamics of a gas solid turbulent fluidized bed reactor. Chem. Eng. Sci 1996, 557, 13-723

[3] Wang, H. G.; Dyakowski, T.; Senior, P.;Raghavan, R. S. ;Yang, W. Q. Modelling of batch fluidized bed drying of pharmaceutical granules. Chem. Eng. Sci 2007a, 62, 1524-1535

[4] Villegas, J.A.; Li, M.; Duncan, S.R. ; Wang, H.G. ;Yang, W.Q. Modeling and control of moisture content in a batch fluidized bed dryer using tomographic sensor. Proceedings of the American Control Conference 2008, 3350-3355

[5] Darton, R.C.; Lanauze, R.D.;Davidson, J.F.; Harrison, D. Bubble growth due to coalescence in fluidized beds. Trans. Inst. Chem. Eng 1977, 55, 274-280

[6] Horio, M.; Nonaka, A. A Generalized Bubble Diameter Correlation for Gas-Solid Fluidized Beds. AIChEJ 1987, 33, 1865-1872

[7] Bi, H.T.; Ellis, N.; Abba, I.A.; Grace, J.R. A state-of-the-art review of gas-solid turbulent fluidization, Chem. Eng. Sci 2000, 55, 4789-4825

[8] Briens, L.; Bojarra, M. Monitoring fluidized bed drying of pharmaceutical granules. AAPS Pharm. Sci. Tech 2010, 11, 1612-1618

[9] Breault, R.W. A review of gas-solid dispersion and mass transfer coefficient correlations in circulating fluidized beds. Powder Technol 2006,163, 9-17 